\title{
Effects of Illuminance and Heat Rays on Photo-Controlled/Living Radical Polymerization Mediated by 4-Methoxy-2,2,6,6-Tetramethylpiperidine-1-Oxyl
}

\author{
Eri Yoshida \\ Department of Environmental and Life Sciences, Toyohashi University of Technology, 1-1 Hibarigaoka, Tempaku-cho Aichi, \\ Toyohashi 441-8580, Japan \\ Correspondence should be addressed to Eri Yoshida, eyoshida@ens.tut.ac.jp
}

Received 18 May 2012; Accepted 4 June 2012

Academic Editors: B. Kiskan and A. V. Popov

Copyright () 2012 Eri Yoshida. This is an open access article distributed under the Creative Commons Attribution License, which permits unrestricted use, distribution, and reproduction in any medium, provided the original work is properly cited.

The effects of illuminance and heat rays released from the light source on the photo-controlled/living radical polymerization of methyl methacrylate were investigated with the aim of strict control of molecular weight. The bulk polymerization was performed at room temperature using 4-methoxy-2,2,6,6-tetramethylpiperidine-1-oxyl as the mediator and (2RS,2'RS)-azobis(4-methoxy2,4-dimethylvaleronitrile) as the initiator in the presence of (4-tert-butylphenyl)diphenylsulfonium triflate as the accelerator by irradiation with a high-pressure mercury lamp. The polymerization by the direct irradiation from the light source yielded polymers containing an uncontrolled high-molecular-weight polymer and having the molecular weight distribution over 3. On the other hand, the polymerization by the indirect irradiation with reflective light using a mirror produced polymers with controlled molecular weights with comparatively narrow molecular weight distribution at ca. 1.4. Too high an illuminance caused an increase in the molecular weight distribution. During the polymerization, the monomer conversion increased as the illuminance increased. It was found that the elimination of heat rays from the illuminating light was indispensable for the molecular weight control by the photo-controlled/living radical polymerization.

\section{Introduction}

Light is a desirable stimulus to manipulate the properties and functions of materials and living organs without damage by heat, such as thermal expansion and deactivation. Photocontrolled systems include the environmental advantage in utilizing solar energy, the significance of local applications, and the use of photo-specific reactions. A significant variety of photo-controlled systems has been created using reversible and also irreversible photoreactions. Examples include the photo-controlled mechanical motion of crystals through the azobenzene photoisomerization [1], the photo-controllable changes in surface morphology of salt crystals by enantiospecific and enantioselective photocyclization of a benzophenone derivative [2], the photo-induced wetting properties on an ultrathin $\mathrm{ZnO}$-coated surface [3], the photo-responsive loading and release of drugs on nanoparticle [4] and nanofiber surfaces [5], self-assembly induced by photo irreversible reactions of photolysis [6-8], photo-rearrangement
[9], and photo onium salt formation [10] for block copolymers, size change of core-shell nanogel particles through the photodimerization and photocleavage of coumarin [11], magnetization of CdS-modified nanoparticles by photoinduced electron transfer from CdS to Prussian blue [12], DNA cleavage by the combination of the photoactive $\mathrm{Zn}$ (II) cooperation and the azobenzene photoisomerization [13], the inhibition of telomerase activity by photo-cross-linking [14], and the photoswitch to induce paralysis in a living organism using the photocyclization of bis(pyridinium)dithienylethene [15].

The photo-controlled/living radical polymerization is also a photo-controllable system that can regulate the molecular weight of a polymer. Photo-living radical polymerization systems have been discovered using various mediators; dithiocarbamate derivatives [16-18], $N, N, N^{\prime}, N^{\prime}-$ tetraethylthiuram disulfide [19], dibenzyl trithiocarbonate [20], 4-thiobenzoyl sulfanylmethyl benzoate [21], bis (2,4,6trimethylbenzoyl)phenylphosphine oxide, bis(4-methoxybe- 


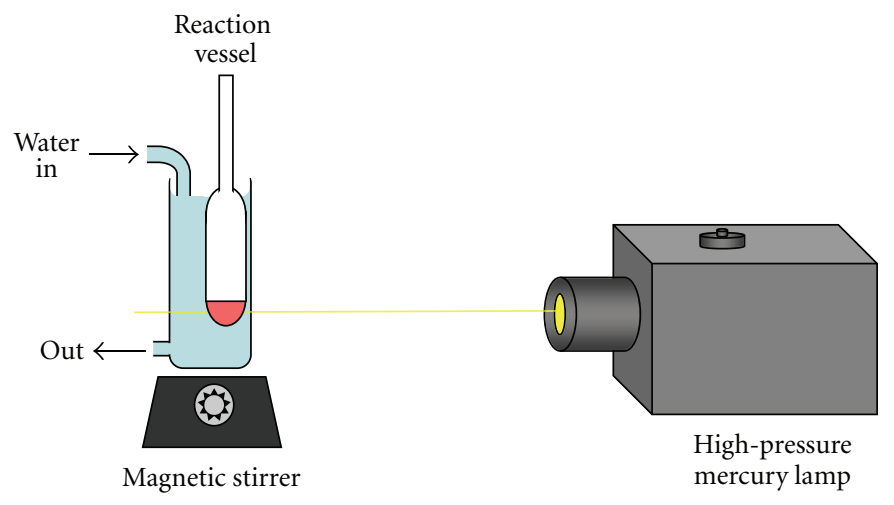

FIGURE 1: A schematic of the photopolymerization with direct irradiation.

nzoyl)diethylgermanium [22], and manganese complex [23]. In recent years, the photo-controlled/living radical polymerization mediated by 2,2,6,6-tetramethylpiperidine-1-oxyl (TEMPO) has been established for methacrylate monomers that could not be applied to the thermal TEMPO-mediated polymerization [24-36] due to the disproportionation termination at high temperature. This TEMPO-mediated photopolymerization was accelerated by the photo-acid generators of the diaryliodonium salts $[24,25]$ and triarylsulfonium salts [28] and produced polymers with the comparatively narrow molecular weight distributions of ca. 1.4 even at a high conversion. However, there is no report concerning the effects of illuminance and heat released from the light source on the photo-controlled polymerization. It was found that the illuminance and heat from the light source affected the polymerization rate and molecular weight control. This paper describes the influences of illuminance and heat from the light source of a high-pressure mercury lamp on the TEMPO-mediated photo-controlled/living radical polymerization of methyl methacrylate (MMA).

\section{Experimental}

2.1. Instrumentation. The photopolymerization was carried out using an Ushio optical modulex BA-H502, an illuminator OPM2-502H with a high-illumination lens UI-OP2SL, and a $500 \mathrm{~W}$ super high-pressure UV lamp (USH-500SC2, Ushio Co. Ltd.). The illuminance was measured using a Topcon IM-5 illuminance meter. Gel permeation chromatography (GPC) was performed using a Tosoh GPC-8020 instrument equipped with a DP-8020 dual pump, a CO-8020 column oven, and a RI-8020 refractometer. Three polystyrene gel columns, Tosoh TSKGEL G2000H $\mathrm{HL}_{\mathrm{XL}}, \mathrm{G} 4000 \mathrm{H}_{\mathrm{XL}}$, and $\mathrm{G} 6000 \mathrm{H}_{\mathrm{XL}}$ were used with tetrahydrofuran as the eluent at $40^{\circ} \mathrm{C}$.

2.2. Materials. 4-Methoxy-TEMPO (MTEMPO) was prepared as reported previously [37]. (2RS,2'RS)-Azob-is(4methoxy-2,4-dimethylvaleronitrile) ( $r$-AMDV) was obtained by separation from a mixture of the racemic and meso forms of 2,2'-azobis(4-methoxy-2,4-dimethylvaleronitrile)

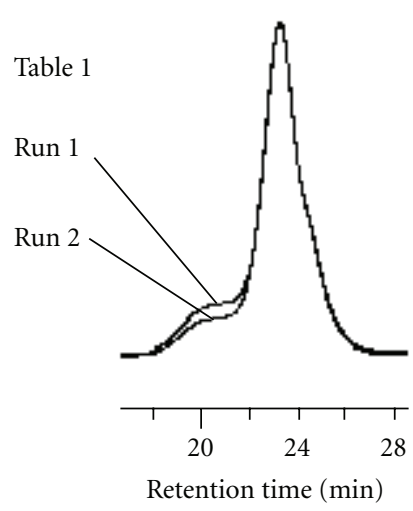

FIGURE 2: GPC profiles of the polymers obtained by the polymerization with the direct irradiation.

[38]. Commercial grade MMA was washed with 5 wt.\% sodium hydroxide solution and water and distilled over calcium hydride. (4-tert-Butylphenyl)-diphenylsulfonium triflate $\left({ }^{t} \mathrm{BuS}\right)$ was purchased from Sigma-Aldrich and used as received. A heat ray absorbent filter, HA30 and a neutral density filter, ND-50 were purchased from Hoya Candeo Optronics Corporation.

2.3. Polymerization by Indirect Irradiation. MMA $(936.0 \mathrm{mg}$, $9.35 \mathrm{mmol}), r$-AMDV (14.0 mg, $0.0454 \mathrm{mmol}$ ), MTEMPO $(9.0 \mathrm{mg}, 0.0483 \mathrm{mmol})$, and ${ }^{t} \mathrm{BuS}(11.0 \mathrm{mg}, 0.0235 \mathrm{mmol})$ were placed in an ampoule. After degassing the contents, the ampoule was sealed under vacuum. The bulk polymerization was carried out at room temperature for $7 \mathrm{~h}$ with irradiation at $5.0 \times 10^{5}$ lux by reflective light using a mirror with a $500 \mathrm{~W}$ high-pressure mercury lamp. The product was dissolved in dichloromethane $(10 \mathrm{~mL})$. The solution was concentrated by an evaporator to remove the dichloromethane and unreacted monomer and was freeze-dried with benzene $(20 \mathrm{~mL})$ at $40^{\circ} \mathrm{C}$ to obtain the product as white powder $(545.8 \mathrm{mg}$ ). The monomer conversion was estimated gravimetrically. The product was dissolved in dichloromethane $(3 \mathrm{~mL})$ and poured into hexane $(500 \mathrm{~mL})$. The precipitate was collected by filtration and dried in vacuo for several hours to be subjected to GPC analysis. 


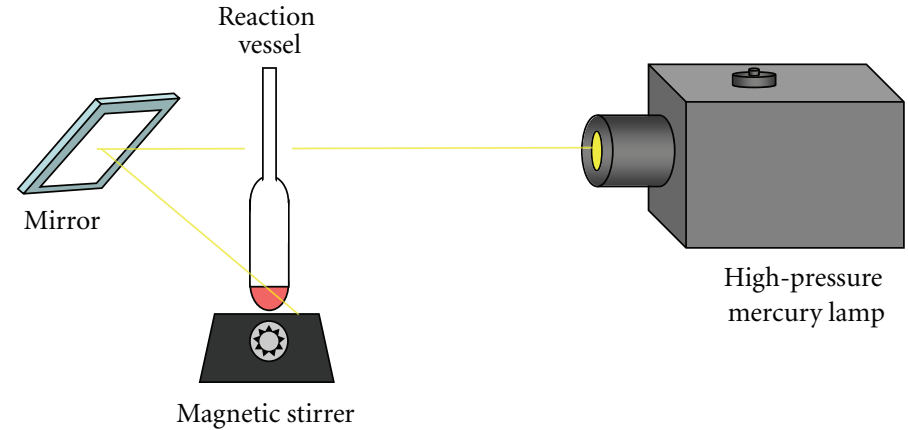

FIGURE 3: A schematic of the photopolymerization with indirect irradiation by reflective light.

TABLE 1: The MMA polymerization with direct irradiation.

\begin{tabular}{|c|c|c|c|c|c|c|c|}
\hline Run No. & Filter & Illuminance $\left(\times 10^{-5}\right.$ lux $)$ & Time (h) & Conversion (\%) & $\mathrm{Mn}\left(\right.$ theor) ${ }^{\mathrm{a}}$ & $\operatorname{Mn}(\text { obs })^{\mathrm{a}}$ & $\mathrm{Mw} / \mathrm{Mn}^{\mathrm{a}}$ \\
\hline 1 & - & 32.5 & 2.5 & 70 & 13,600 & 12,500 & 5.04 \\
\hline 2 & - & 25.7 & 2.5 & 66 & 12,900 & 12,600 & 3.35 \\
\hline 3 & HA30 + ND50 & 11.6 & 6 & 0 & - & - & - \\
\hline
\end{tabular}

$\mathrm{MTEMPO} / r$-AMDV $=1.06,{ }^{t} \mathrm{BuS} / \mathrm{MTEMPO}=0.486$.

aEstimated by GPC based on poly(MMA) standards.

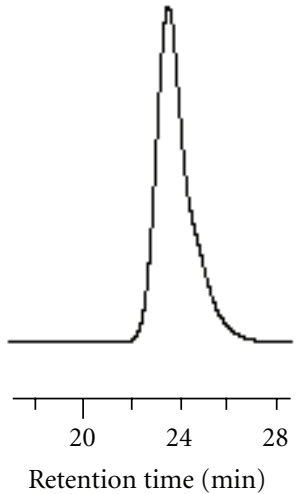

FIGURE 4: The GPC profile of the polymer obtained by the polymerization with the indirect irradiation at $5.0 \times 10^{5}$ lux.

\section{Results and Discussion}

The photo-controlled/living radical polymerization of MMA was performed at room temperature using the $r$-AMDV initiator and the MTEMPO mediator in the presence of the ${ }^{t} \mathrm{BuS}$ accelerator. The bulk polymerization was carried out at different illuminances by direct irradiation in a water bath to avoid a rise in the temperature of the reaction system by the direct irradiation (Figure 1). The results are shown in Table 1. The polymerization rapidly proceeded by the direct irradiation and provided very broad molecular weight distributions of $\mathrm{Mw} / \mathrm{Mn}>3$. The GPC analysis revealed that the resulting polymers contained uncontrolled highmolecular-weight polymers. As can be seen in Figure 2, the proportion of the high-molecular-weight polymer was reduced as a result of decreasing the illuminance. In addition, no polymerization occurred by the direct irradiation through

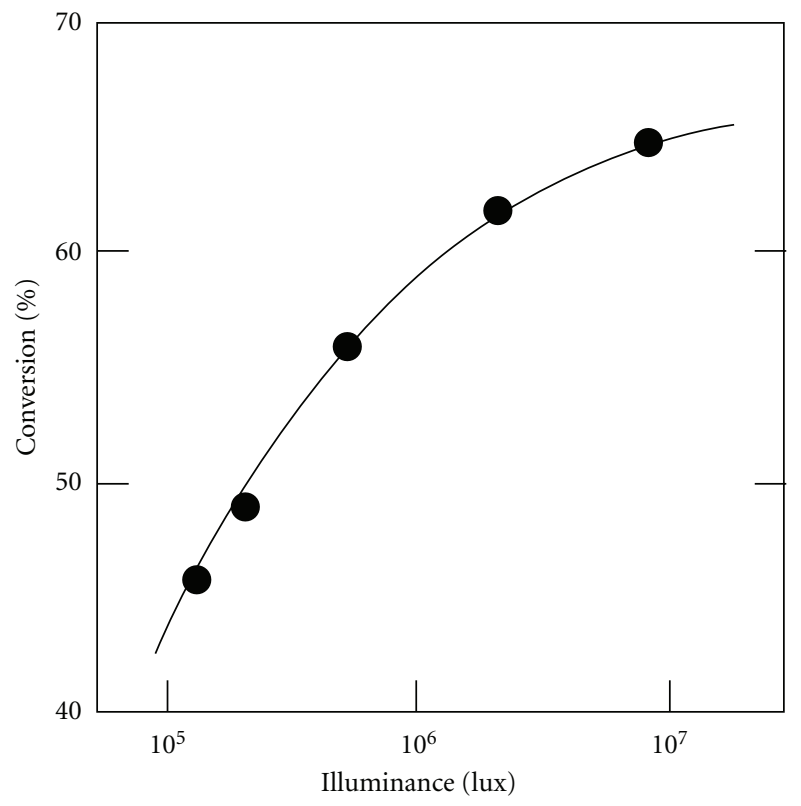

FIGURE 5: The plots of the monomer conversion versus the illuminance for the polymerization with the indirect irradiation.

a heat ray absorbent filter, HA30, that can exclude the rays with the wavelengths over ca. $900 \mathrm{~nm}$ and a neutral density filter, ND-50, that reduces the illuminance to $50 \%$.

In order to avoid the influence of heat rays on the polymerization, the polymerization was performed with the indirect irradiation by a reflective light using a mirror. This indirect irradiation can exclude heat rays of wavelengths around $1,100 \mathrm{~nm}$ included in the light from the mercury lamp because the heat rays are not reflected by a mirror. A schematic of the polymerization with the indirect irradiation 
TABLE 2: The MMA polymerization with indirect irradiation.

\begin{tabular}{|c|c|c|c|c|c|c|}
\hline Filter & Illuminance $\left(\times 10^{-5} \operatorname{lux}\right)$ & Time $(\mathrm{h})$ & Conversion (\%) & Mn (theor) & $\operatorname{Mn}(\text { obs })^{\mathrm{a}}$ & $\mathrm{Mw} / \mathrm{Mn}^{\mathrm{a}}$ \\
\hline - & 1.3 & 7 & 46 & 9,240 & 9,230 & 1.42 \\
\hline 一 & 1.9 & 7 & 49 & 9,820 & 9,690 & 1.49 \\
\hline 一 & 5.0 & 7 & 56 & 11,200 & 9,950 & 1.45 \\
\hline 一 & 20.1 & 7 & 62 & 12,300 & 10,900 & 1.43 \\
\hline 一 & 80.4 & 7 & 65 & 12,900 & 10,800 & 1.53 \\
\hline HA30 & 4.4 & 7.5 & 15 & 3,230 & 3,260 & 1.60 \\
\hline HA30 & 110.0 & 6 & 24 & 4,980 & 5,640 & 1.59 \\
\hline
\end{tabular}

$\mathrm{MTEMPO} / r$-AMDV $=1.06,{ }^{t} \mathrm{BuS} / \mathrm{MTEMPO}=0.486$.

${ }^{a}$ Estimated by GPC based on poly(MMA) standards.
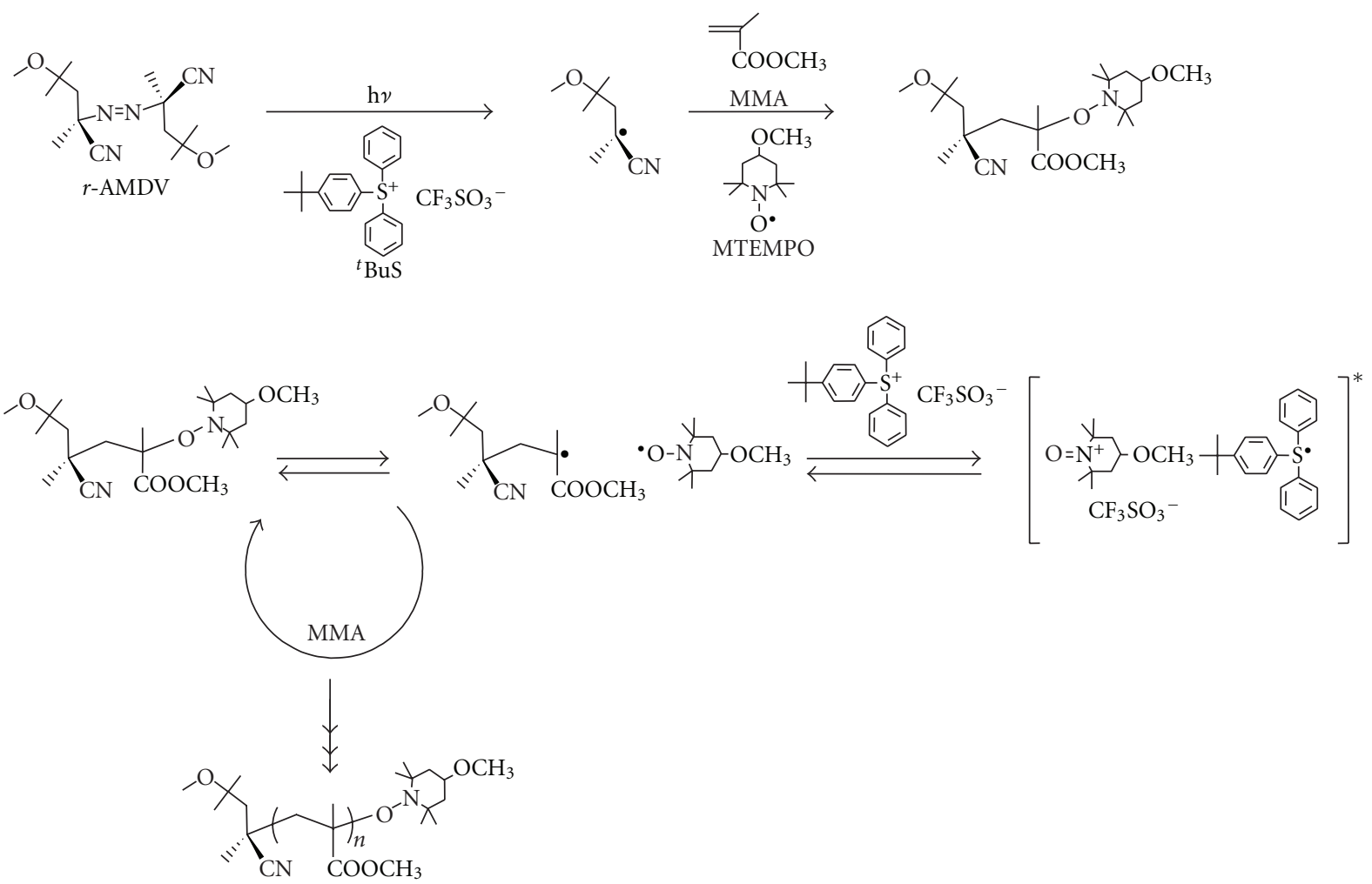

FIgURE 6: The mechanism of the MTEMPO-mediated photo-controlled/living polymerization in the presence of ${ }^{t} \mathrm{BuS}$.

is shown in Figure 3. The results of the polymerization are shown in Table 2.

The indirect irradiation polymerization produced polymers with controlled molecular weights without any uncontrolled high-molecular-weight polymers. The experimental molecular weights, Mn (obs), were in good agreement with the theoretical molecular weights, Mn (theor). The GPC profile of the resulting polymer obtained at a $5.0 \times 10^{5}$ luxilluminance is shown in Figure 4. Figure 5 shows the plots of the monomer conversion versus the illuminance. An increase in the illuminance accelerated the polymerization. However, too high an illuminance increased molecular weight distribution and produced a deviation in the molecular weight from the theoretical one. The polymerization at too high an illuminance may be influenced by the heat released from the light source because the distance from the light source to the reaction vessel was quite short $(12.5 \mathrm{~cm})$. The elimination of heat rays using HA30 decelerated the polymerization. This deceleration can be accounted for by the fact that this heat ray absorbent filter eliminates not only rays over $900 \mathrm{~nm}$, but also rays below $270 \mathrm{~nm}$. When it is taken into consideration that ${ }^{t} \mathrm{BuS}$ has a UV absorption at $\lambda_{\max }=238 \mathrm{~nm},{ }^{t} \mathrm{BuS}$ was not excited by the irradiation through HA30, resulting in the fact that ${ }^{t} \mathrm{BuS}$ should not have served as the accelerator. The irradiation through HA30 also caused an increase in the molecular weight distribution probably due to the deceleration of the initiation. This implies that the excited ${ }^{t} \mathrm{BuS}$ also accelerates the decomposition of the initiator. The proposed mechanism throughout the polymerization is shown in Figure 6. It can be deduced that the elimination of 
only heat rays that cause the uncontrolled polymerization is significant for controlling the molecular weight of a polymer.

\section{Conclusion}

This is the first study clarifying the influence of heat rays on the photo-controlled/living radical polymerization mediated by MTEMPO. The heat rays caused uncontrolled polymerization during the MTEMPO-mediated photopolymerization. A decrease in the illuminance reduced the proportion of a polymer with an uncontrolled molecular weight. The exclusion of heat rays is indispensable for the molecular weight control. However, the use of a heat ray absorbent filter is ineffective for controlling the molecular weight because the filter also eliminated the rays below $270 \mathrm{~nm}$ when the accelerator with the UV absorption below this wavelength was used for the polymerization. The indirect irradiation by reflective light using a mirror effectively controlled the molecular weight by the TEMPO-mediated photopolymerization.

\section{References}

[1] H. Koshima, N. Ojima, and H. Uchimoto, "Mechanical motion of azobenzene crystals upon photoirradiation," Journal of the American Chemical Society, vol. 131, no. 20, pp. 6890-6891, 2009.

[2] H. Koshima, Y. Ide, S. Yamasaki, and N. Ojima, "Changes in the surface morphology of salt crystals of 4-(2,5- Diisopropylbenzoyl)benzoic acid with amines via single-crystal-to-singlecrystal photocyclization," Journal of Physical Chemistry C, vol. 113, no. 27, pp. 11683-11688, 2009.

[3] J. Malm, E. Sahramo, M. Karppinen, and R. H. A. Ras, "Photocontrolled wettability switching by conformal coating of nanoscale topographies with ultrathin oxide films," Chemistry of Materials, vol. 22, no. 11, pp. 3349-3352, 2010.

[4] Y. Wang, P. Han, H. Xu, Z. Wang, X. Zhang, and A. V. Kabanov, "Photocontrolled self-assembly and disassembly of block ionomer complex vesicles: A facile approach toward Supramolecular Polymer nanocontainers," Langmuir, vol. 26, no. 2, pp. 709-715, 2010.

[5] G.-D. Fu, L.-Q. Xu, F. Yao, G.-L. Li, and E.-T. Kang, "Smart nanofibers with a photoresponsive surface for controlled release," ACS Applied Materials and Interfaces, vol. 1, no. 11, pp. 2424-2427, 2009.

[6] X. Tong, G. Wang, A. Soldera, and Y. Zhao, "How can azobenzene block copolymer vesicles be dissociated and reformed by light?" Journal of Physical Chemistry B, vol. 109, no. 43, pp. 20281-20287, 2005.

[7] E. Yoshida and S. Kuwayama, "Micelle formation induced by photolysis of a poly(tert-butoxystyrene)-block-polystyrene diblock copolymer," Colloid \& Polymer Science, vol. 285, no. 11, pp. 1287-1291, 2007.

[8] E. Yoshida and S. Kuwayama, "Photolysis-induced micellization of a poly(4-tert-butoxystyrene)-block-polystyrene diblock copolymer," Colloid \& Polymer Science, vol. 286, no. 14-15, pp. 1621-1627, 2008.

[9] E. Yoshida and S. Kuwayama, "Micelle formation induced by photo-Claisen rearrangement of poly(4-allyloxystyrene)block-polystyrene," Colloid \& Polymer Science, vol. 287, no. 7, pp. 789-793, 2009.
[10] E. Yoshida, S. Kuwayama, and S. Kawaguchi, "Photo-induced micellization of poly(4-pyridinemethoxymethylstyrene)block-polystyrene using a photo-acid generator," Colloid \& Polymer Science, vol. 288, no. 1, pp. 91-95, 2010.

[11] J. He, B. Yan, L. Tremblay, and Y. Zhao, "Both core- and shellcross-linked nanogels: Photoinduced size change, intraparticle LCST, and interparticle UCST thermal behaviors," Langmuir, vol. 27, no. 1, pp. 436-444, 2011.

[12] M. Taguchi, I. Yagi, M. Nakagawa, T. Iyoda, and Y. Einaga, "Photocontrolled magnetization of CdS-modified prussian blue nanoparticles," Journal of the American Chemical Society, vol. 128, no. 33, pp. 10978-10982, 2006.

[13] A. Panja, T. Matsuo, S. Nagao, and S. Hirota, "DNA cleavage by the photocontrolled cooperation of $\mathrm{Zn}^{\text {II }}$ centers in an azobenzene-linked dizinc complex," Inorganic Chemistry, vol. 50, no. 22, pp. 11437-11445, 2011.

[14] Y. Xu, K. Ito, Y. Suzuki, and M. Komiyama, "A 6-mer photocontrolled oligonucleotide as an effective telomerase inhibitor," Journal of the American Chemical Society, vol. 132, no. 2, pp. 631-637, 2010.

[15] U. Al-Atar, R. Fernandes, B. Johnsen, D. Baillie, and N. R. Branda, "A photocontrolled molecular switch regulates paralysis in a living organism," Journal of the American Chemical Society, vol. 131, no. 44, pp. 15966-15967, 2009.

[16] T. Otsu and A. Kuriyama, "Living mono- and biradical polymerizations in homogeneous system synthesis of $\mathrm{AB}$ and ABA type block copolymers," Polymer Bulletin, vol. 11, no. 2, pp. 135-142, 1984.

[17] M. A. Tasdelen, Y. Y. Durmaz, B. Karagoz, N. Bicak, and Y. Yagci, "A new photoiniferter/RAFT agent for ambient temperature rapid and well-controlled radical polymerization," Journal of Polymer Science, Part A, vol. 46, no. 10, pp. 33873395, 2008.

[18] J. Lalevée, X. Allonas, and J. P. Fouassier, "A new efficient photoiniferter for living radical photopolymerization," Macromolecules, vol. 39, no. 24, pp. 8216-8218, 2006.

[19] T. Doi, A. Matsumoto, and T. Otsu, "Elucidation of mechanism for living radical polymerization of styrene with $N, N$ diethyldithiocarbamate derivatives as iniferters by the use of spin trapping technique," Journal of Polymer Science, Part A, vol. 32, no. 12, pp. 2241-2249, 1994.

[20] Y.-Z. You, C.-Y. Hong, R.-K. Bai, C.-Y. Pan, and J. Wang, "Photo-initiated living free radical polymerization in the presence of dibenzyl trithiocarbonate," Macromolecular Chemistry and Physics, vol. 203, no. 3, pp. 477-483, 2002.

[21] S. E. Shim, Y. Shin, J. W. Jun, K. Lee, H. Jung, and S. Choe, "Living-free-radical emulsion photopolymerization of methyl methacrylate by a surface active iniferter (suriniferter)," Macromolecules, vol. 36, no. 21, pp. 7994-8000, 2003.

[22] K. Krüger, K. Tauer, Y. Yagci, and N. Moszner, "Photoinitiated bulk and emulsion polymerization of styrene-evidence for photo-controlled radical polymerization," Macromolecules, vol. 44, no. 24, pp. 9539-9549, 2011.

[23] K. Koumura, K. Satoh, and M. Kamigaito, "Photoinduced living radical polymerization with highly active manganese complex," Polymer Preprints of the American Chemical Society, vol. 49, no. 2, pp. 230-231, 2008.

[24] E. Yoshida, "Photo-living radical polymerization of methyl methacrylate by a nitroxide mediator," Colloid \& Polymer Science, vol. 286, no. 14-15, pp. 1663-1666, 2008.

[25] E. Yoshida, "Photo-living radical polymerization of methyl methacrylate by 2,2,6,6-tetramethylpiperidine-1-oxyl in the presence of a photo-acid generator," Colloid \& Polymer Science, vol. 287, no. 7, pp. 767-772, 2009. 
[26] E. Yoshida, "Synthesis of poly(methyl methacrylate)-blockpoly(tetrahydrofuran) by photo-living radical polymerization using a 2,2,6,6-tetramethylpiperidine-1-oxyl macromediator," Colloid \& Polymer Science, vol. 287, no. 12, pp. 1417-1424, 2009.

[27] E. Yoshida, "Photo-living radical polymerization of methyl methacrylate using alkoxyamine as an initiator," Colloid \& Polymer Science, vol. 288, no. 1, pp. 7-13, 2010.

[28] E. Yoshida, "Nitroxide-mediated photo-living radical polymerization of methyl methacrylate using (4-tert-butylphenyl)diphenylsulfonium triflate as a photo-acid generator," Colloid \& Polymer Science, vol. 288, no. 2, pp. 239-243, 2010.

[29] E. Yoshida, "Effect of azoinitiators on nitroxide-mediated photo-living radical polymerization of methyl methacrylate," Colloid \& Polymer Science, vol. 288, no. 3, pp. 341-345, 2010.

[30] E. Yoshida, "Effects of initiators and photo-acid generators on nitroxide-mediated photo-living radical polymerization of methyl methacrylate," Colloid \& Polymer Science, vol. 288, no. 8, pp. 901-905, 2010.

[31] E. Yoshida, "Stability of growing polymer chain ends for nitroxide-mediated photo-living radical polymerization," Colloid \& Polymer Science, vol. 288, no. 9, pp. 1027-1030, 2010.

[32] E. Yoshida, "Nitroxide-mediated photo-living radical polymerization of methyl methacrylate in solution," Colloid \& Polymer Science, vol. 288, no. 16-17, pp. 1639-1643, 2010.

[33] E. Yoshida, "Nitroxide-mediated photo-living radical polymerization of methyl methacrylate in the presence of ( $\eta^{6}$-benzene) $\left(\eta^{5}\right.$-cyclopentadienyl) $\mathrm{Fe}^{\mathrm{II}}$ hexafluorophosphate," Colloid \& Polymer Science, vol. 288, no. 18, pp. 1745-1749, 2010.

[34] E. Yoshida, "Graft copolymerization of methyl methacrylate on polystyrene backbone through nitroxide-mediated photoliving radical polymerization," Colloid \& Polymer Science, vol. 289, no. 7, pp. 837-841, 2011.

[35] E. Yoshida, "Nitroxide-mediated photo-controlled/living radical dispersion polymerization of methyl methacrylate," Colloid \& Polymer Science, vol. 289, no. 14, pp. 1625-1630, 2011.

[36] E. Yoshida, "Photo-controlled/living radical polymerization of tert-butyl methacrylate in the presence of a photo-acid generator using a nitroxide mediator," Colloid \& Polymer Science, vol. 290, pp. 661-665, 2012.

[37] T. Miyazawa, T. Endo, S. Shiihashi, and M. Okawara, "Selective oxidation of alcohols by oxoaminium salts $\left(\mathrm{R}_{2} \mathrm{~N}=\mathrm{O}^{+} \mathrm{X}^{-}\right)$," Journal of Organic Chemistry, vol. 50, no. 8, pp. 1332-1334, 1985.

[38] Y. Kita, K. Gotanda, K. Murata et al., "Practical radical additions under mild conditions using 2,2' -azobis(2,4-dimethyl-4methoxyvaleronitrile) [V-70] as an initiator," Organic Process Research and Development, vol. 2, no. 4, pp. 250-254, 1998. 

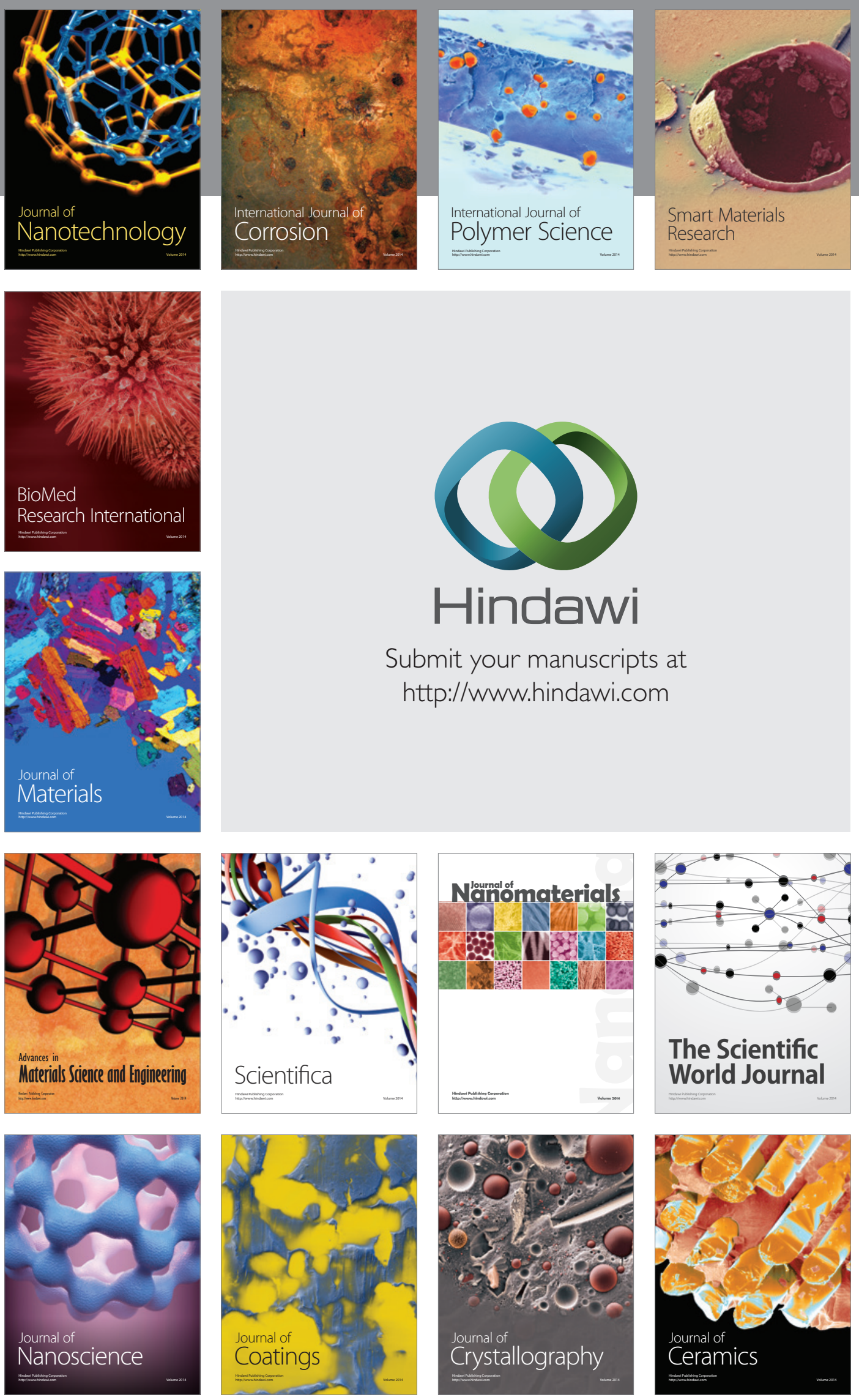

The Scientific World Journal

Submit your manuscripts at

http://www.hindawi.com

\section{World Journal}

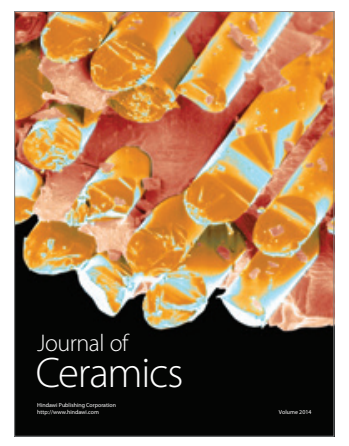

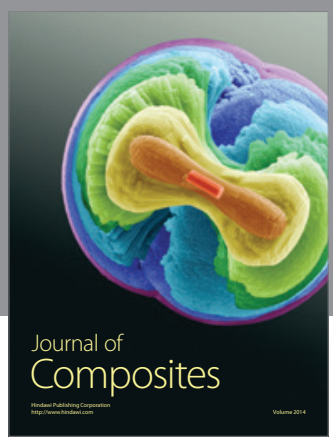
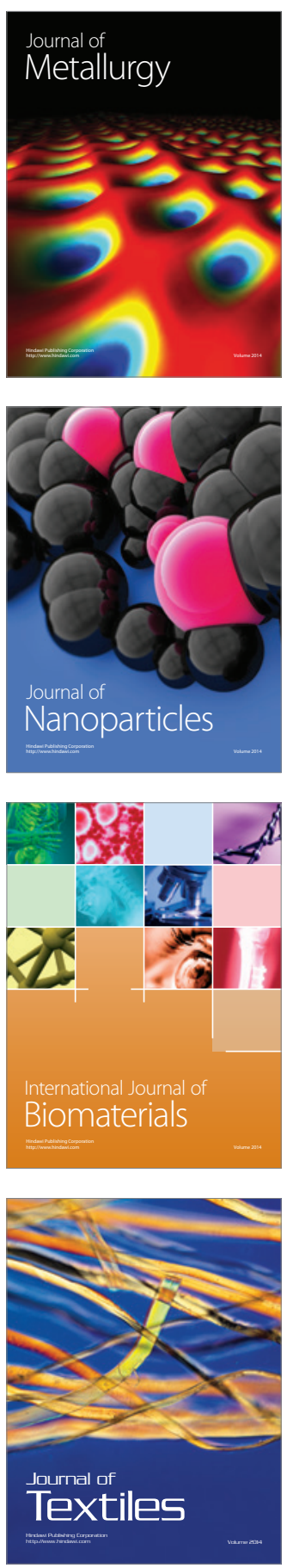